\title{
Correction to: Allelopathic interaction between two common meadow plants: Dactylis glomerata L. and Trifolium pratense L.
}

\author{
Katarzyna Możdżeń ${ }^{1}$ • Beata Barabasz-Krasny ${ }^{1}$ - Alina Stachurska-Swakoń ${ }^{2} \cdot$ Peiman Zandi $^{3} \cdot$ Joanna Puła $^{4}$. \\ Yaosheng Wang $^{3} \cdot$ Ingrid Turisova $^{5}$
}

Published online: 6 April 2020

(C) Slovak Academy of Sciences 2020

\section{Correction to: Biologia}

$$
\text { https://doi.org/10.2478/s11756-020-00438-6 }
$$

Due to an internal figure processing error the article was published with erroneous renderings of Figs. 1, 2, and 3. The publisher regrets the error and this correction stands to note and correct the discrepancies. The original article has been corrected.

The online version of the original article can be found at https://oi.org/ 10.2478/s11756-020-00438-6

Katarzyna Możdżeń

katarzyna.mozdzen@up.krakow.pl

1 Institute of Biology, Pedagogical University of Krakow,

Podchorążych 2, 30-084 Kraków, Poland

2 Institute of Botany, Jagiellonian University, Gronostajowa 3, 30-387 Kraków, Poland

3 Institute of Environment and Sustainable Development in Agriculture, Chinese Academy of Agricultural Science, Beijing 100081, People's Republic of China

4 Faculty of Agriculture and Economics, University of Agriculture, Mickiewicza 21 Ave, 31-120 Kraków, Poland

5 Department of Biology and Ecology, Faculty of Natural Sciences, Matej Bel University in Banska Bystrica, Tajovského 40, 974

01 Banská Bystrica, Slovakia 

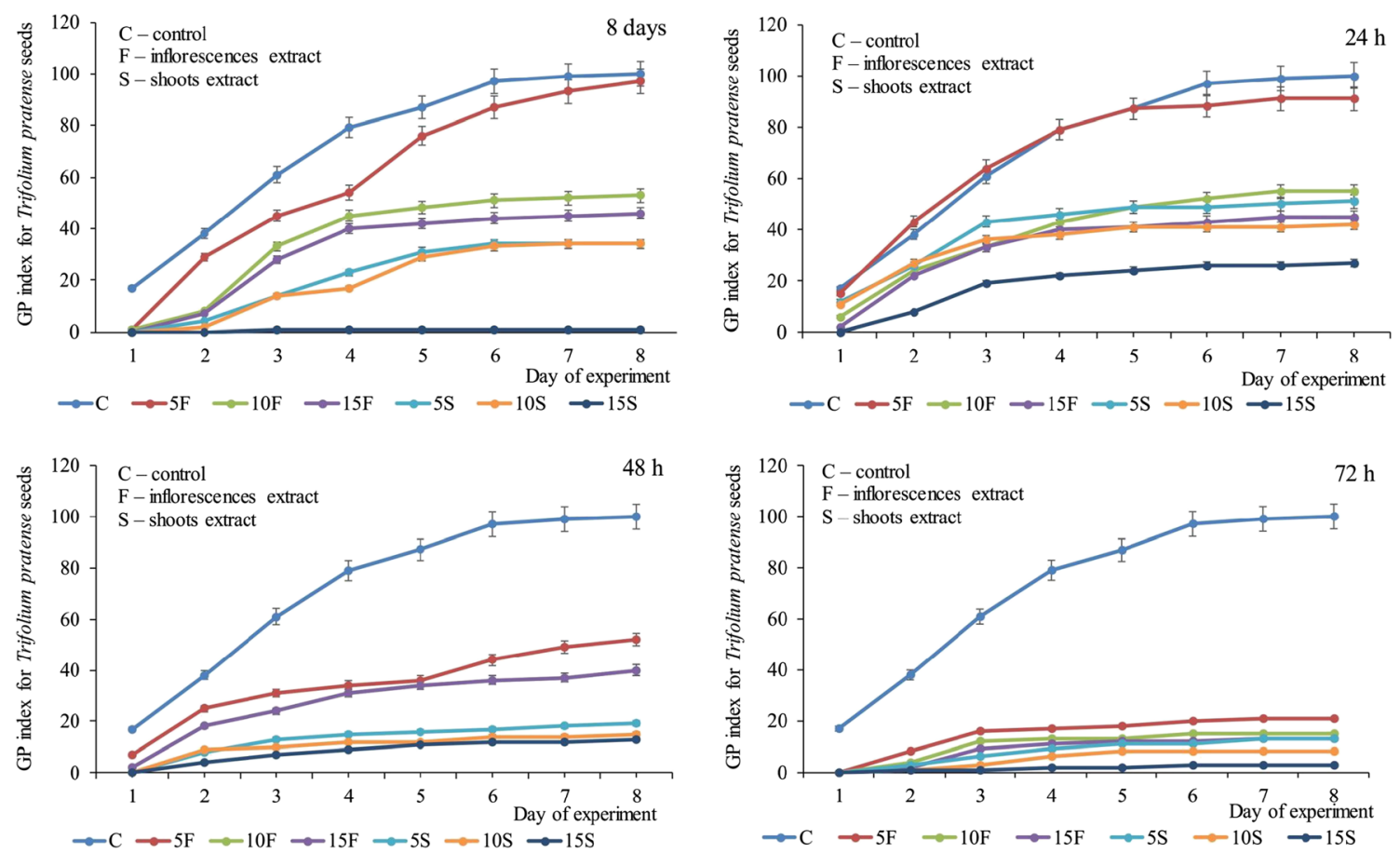

Fig. 1

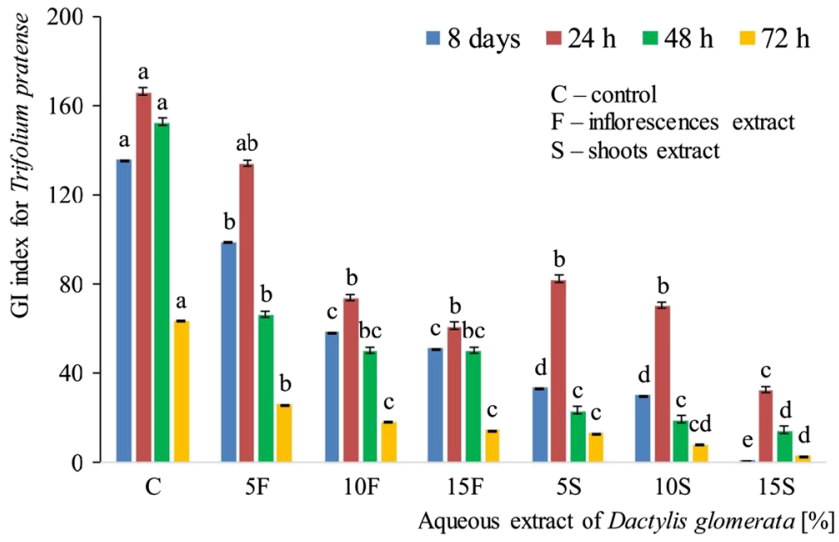

Fig. 2 

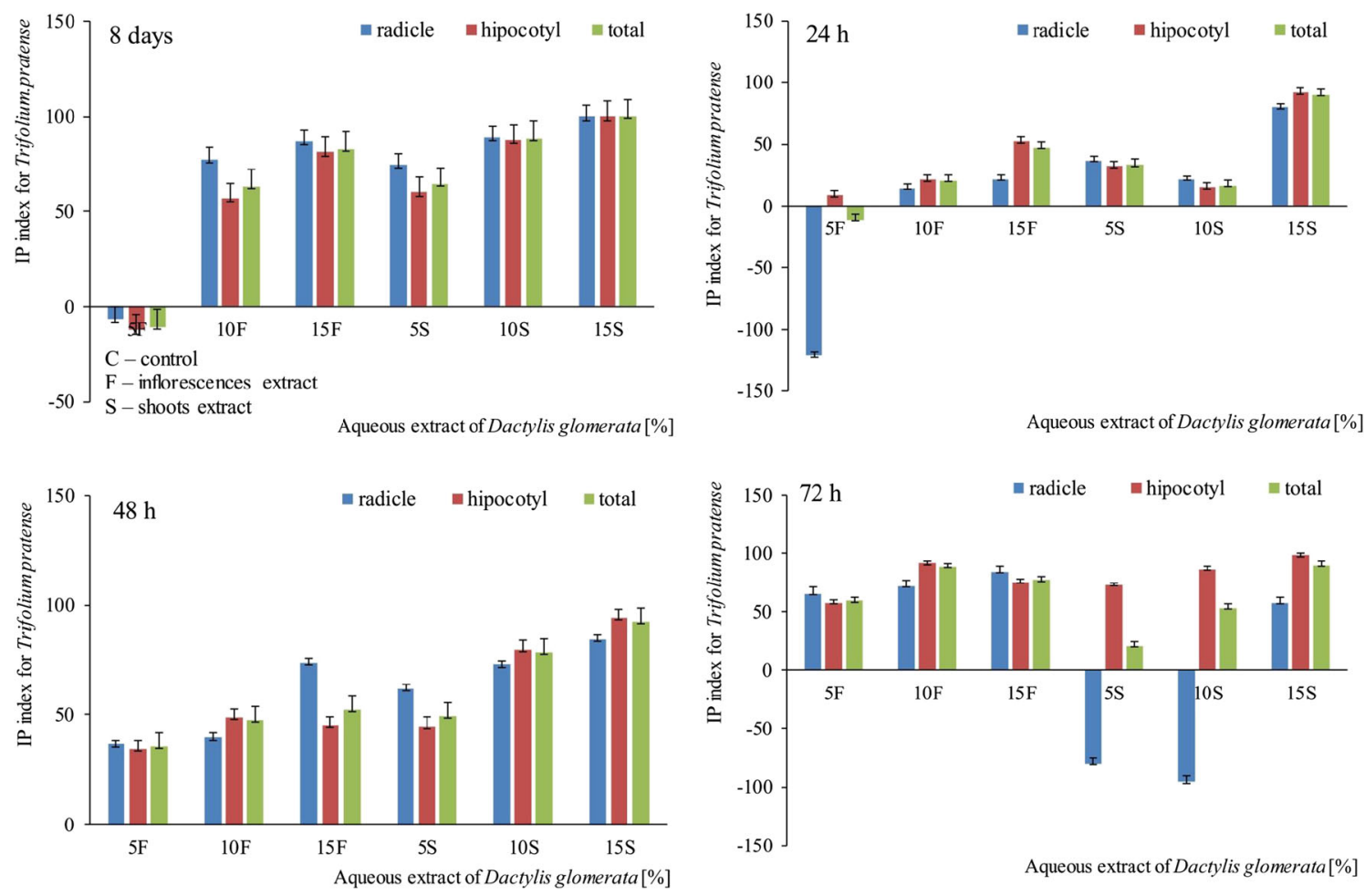

Fig. 3

Publisher's note Springer Nature remains neutral with regard to jurisdictional claims in published maps and institutional affiliations. 